\title{
COMPARISON OF TWO DIFFERENT APPROACHES FOR THE SEISMIC EVALUATION OF THE BONET BUILDING OF THE NATIONAL PALACE OF SINTRA, PORTUGAL
}

\author{
M. PONTE ${ }^{1 *}$, M. MALCATA ${ }^{1}$, AND R. BENTO $^{1}$ \\ ${ }^{1}$ Civil Engineering Research and Innovation for Sustainability (CERIS) \\ Instituto Superior Técnico (IST), Universidade de Lisboa \\ Av. Rovisco Pais, 1049-001 Lisboa, Portugal \\ e-mail: \{madalenaponte, madalena.malcata, rita.bento\}@tecnico.ulisboa.pt
}

Keywords: Seismic Assessment, Cultural Heritage, Equivalent Frame Method, Finite Element Model

\begin{abstract}
Complex masonry monuments represent an important part of the built cultural heritage and most of them are vulnerable to seismic actions. Their large scale, irregularity, and heterogeneity makes it challenging to characterize their structural behaviour.

This work addresses the state of conservation as well as the structural behaviour and seismic vulnerability of the most ancient body of the National Palace of Sintra, Portugal: the Bonet building. This body was built on top of Arabic foundations during the reign of King Dinis, around the year 1281, and since then few alterations were made to the building.

In order to minimize the multiple uncertainties usually existing in complex masonry buildings, whether related to geometry or masonry mechanical properties, a detailed structural survey was conducted together with different in-situ experimental tests. All the tests performed were important to the adequate characterization of the building and the calibration of the numerical models. The final values adopted for the mechanical properties of the rubble stone masonry are presented and can be used as a reference for future works in ancient Portuguese monuments of the same period.

Afterwards, nonlinear static analyses were performed in two different software (3MURI and ABAQUS). Comparisons and discussion of the results are made. The differences in modelling strategies and characterization of materials between the two software are considered with regard to their realism, computational effort, data availability and applicability to large scale structures. Efforts to calibrate and obtain the same behaviour of the building for the different software were made, involving geometry, boundary conditions and characterization of the material constitutive laws.
\end{abstract}

\section{INTRODUCTION}

This work is part of a research project which aims to evaluate the seismic safety of the National Palace of Sintra, by identifying possible structural anomalies and vulnerability factors. This project was developed by Instituto Superior Técnico, University of Lisbon and promoted by Parques de Sintra - Monte da Lua, S.A. (PSML). The palace is an agglomerate of buildings 
of different volumes and styles added over time that presents a beautiful and harmonious unity, characterized by its iconic chimneys, as can be seen in Figure 1.
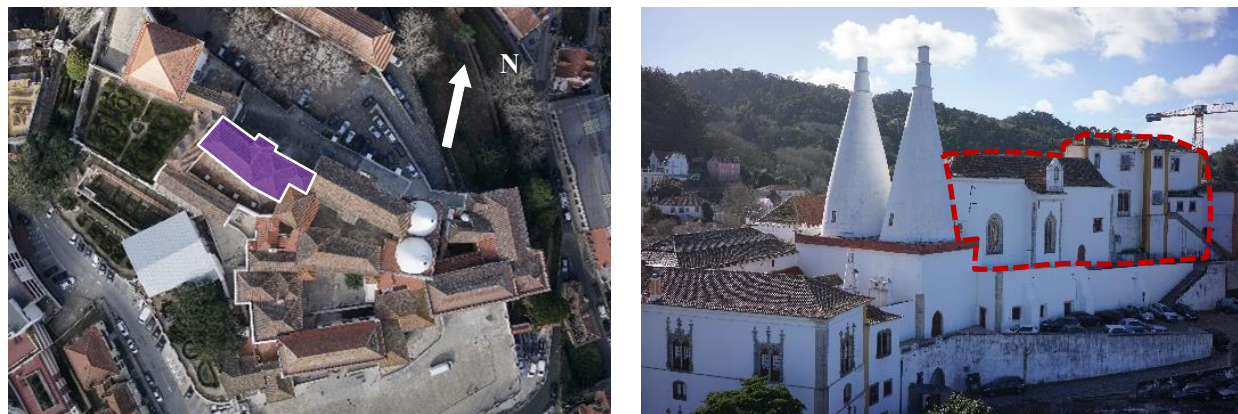

Figure 1: On the left: North-facing top picture of the National Palace of Sintra. On the right: Northeast view of the palace with the identification of the Bonet Building and the chapel (images captured by the drone of the

This study aims at the structural safety verification of the Bonet Building, one of the oldest structures from the National Palace of Sintra, built over the foundations of an ancient Arab palace. At the request of King D. Dinis, whose reign took place between 1261 and 1326, the Bonet Building was expanded, and the adjacent Palatine Chapel building was built from scratch, both identified in Figure 1 (right)

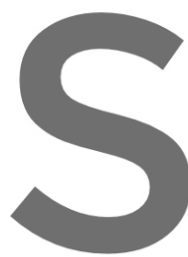

The palace is locate mainland characterized structures such as this difficulties. One of the needs to choose betwee
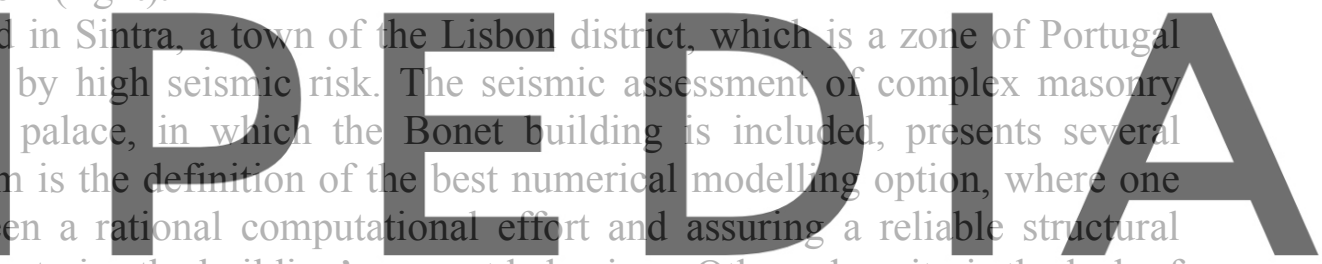

assessment able to characterize the building's correct behaviour. Other adversity is the lack of

Register for free athististent wrocedures the perform the seismic analysis and verification of such complex masonry structures ([1], [2]).

For the complete characterization of the Bonet building, an experimental campaign was carried out including in-situ experimental tests aiming for the mechanical characterization of materials and/or structural elements, and the geometric and dynamic identification of the structure [3]. A detailed geometric inspection was performed using a laser scanner that allowed to obtain data with an accuracy of up to $1 \times 10^{-6} \mathrm{~m}$, thus constituting a suitable methodology for cases of complex geometry. The data collection was aided by a UAV equipped with a Sony $7 \mathrm{R}$ digital camera so that it was possible to obtain full information of the outside of the palace. The set of data obtained gave rise to a three-dimensional point cloud (Figure 2, left), later treated and used in Revit software for the development of an H-BIM model (Figure 2, right).

The GPR (Ground Penetrating Radar) test, a non-destructive method, aims to characterize the masonry by detecting types of materials and anomalies (voids, cracks, water), using different frequencies' antennas. With this test, two major conclusions were obtained: i) "the majority of the walls are composed of two interior-filled masonry leaves, and usually the outer leaf is approximately $0.30 \mathrm{~m}$ thick" [4]; and ii) the walls built around the rock are directly in contact with it, without empty spaces in between. 

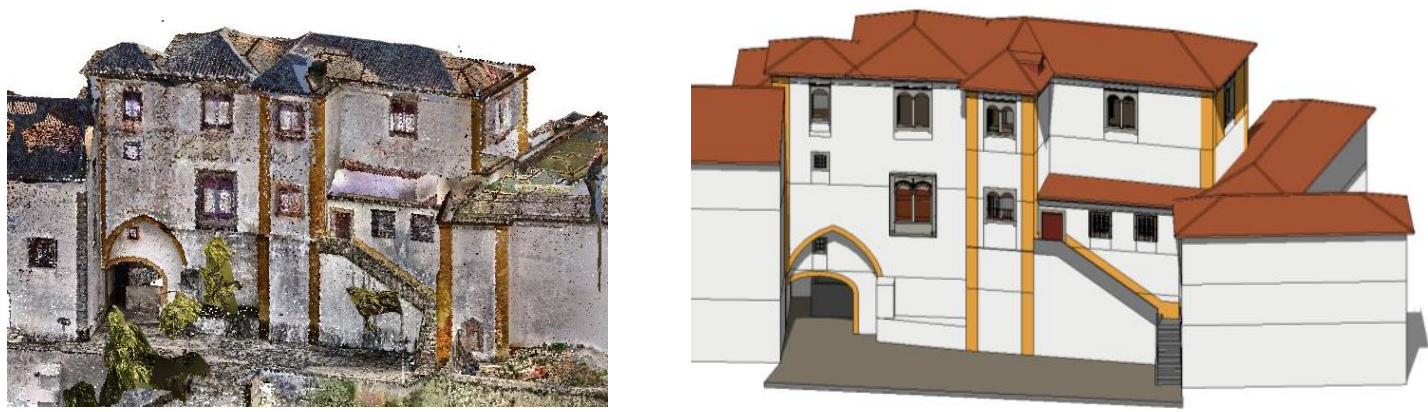

Figure 2: Bonet Building, North Facade: Point clouds (on the left) and Revit Model (on the right)

Flat-jack tests, considered to be semi-destructive, aim to characterize the mechanical capacity of structural masonry walls. The fact that Bonet is a historical building increases the difficulty of locating the experimental tests. Despite this, the wall to be tested should accomplish still the following conditions: to present a certain level of compression and not be located near doors, windows, or another singularity that can alter the stress field. With this in mind, two locations were defined, one on the north facade of the building and the other on the south. The results of the single test indicate that the Bonet structure is poorly compressed in the tested areas, although the results may be considered with caution due to their punctual character and the physical characteristics of the walls, which present high thicknesses. From the double tests, the stress-strain curves were obtained Poisson's ratio were detert conditions of the wall locations on the buildin into account only as an In addition, samples were dollected in the
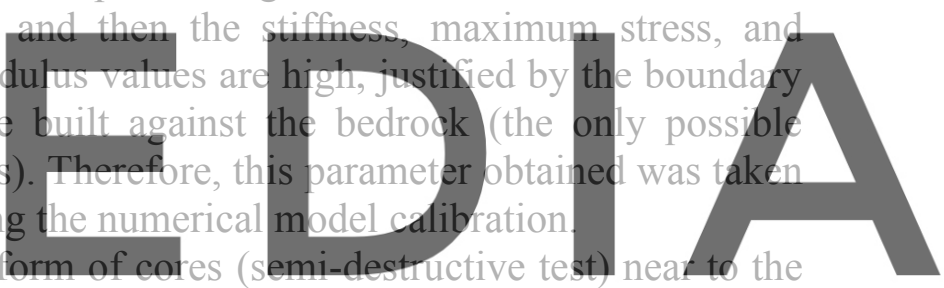

locations were the flat-jack tests were carried out, in order to characterize the material and its

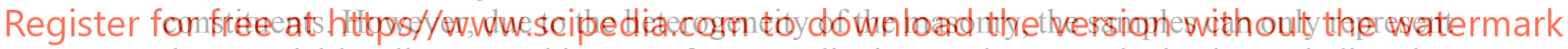
the material locally. From this type of test, qualitative results were obtained, concluding that the state of degradation of the masonry in the Bonet building is quite high, even one of the worst of the entire palace [3].

The ambient vibration tests are non-destructive and suitable for the seismic assessment of existing buildings, especially for historic and heritage buildings. By measuring the structure vibrations subjected to external environmental inputs, it is possible to identify the modal dynamic characterization parameters. The dynamic characterization of the structure is crucial for the calibration of its numerical model. The processing of the obtained data was performed with the ARTeMIS Modal Pro software [5] that allowed to obtain the fundamental frequencies and the vibration modes of the structure. Results reached are available further on in Table 1 and Figure 4.

\section{NUMERICAL MODEL}

The Bonet Building was modelled in parallel using two software, 3Muri [6] and ABAQUS [7]. For both models, it was ensured that the structure geometry is identical, even with the required simplifications, and consistent with the data collected by the Laser Scanner. 
Both ABAQUS and 3Muri models were defined based on the BIM model. It was decided to export the Revit model [8] and to import it into ABAQUS, saving time and significant manual effort. In 3Muri, this specific option is not possible. Nevertheless, one should be aware of the usual excessive detailing in BIM models for the purposes of numerical modelling, with all the architectural ornamentation, that cannot be directly used in FE software. Thus, as explained in [9], in order to achieve an adequate FE model, several manual simplifications are required to guarantee mesh compatibility, to avoid mesh local distortions or small elements, and to model complex architectural objects. With that in mind, some geometric simplifications were adopted, namely the use of the mean value of thickness in walls of variable thicknesses.

For the ABAQUS model, in solid FE elements, a 10-node tetrahedral finite element mesh with a maximum size of $700 \mathrm{~mm}$ was defined (Figure 3, left), thus ensuring for each thickness the existence of three nodes. As presented in Figure 3 (right), the EF method is adopted in 3Muri [3], defining the walls in macroelements that consist of piers (represented in orange), spandrels (in green), and rigid nodes (in light blue).

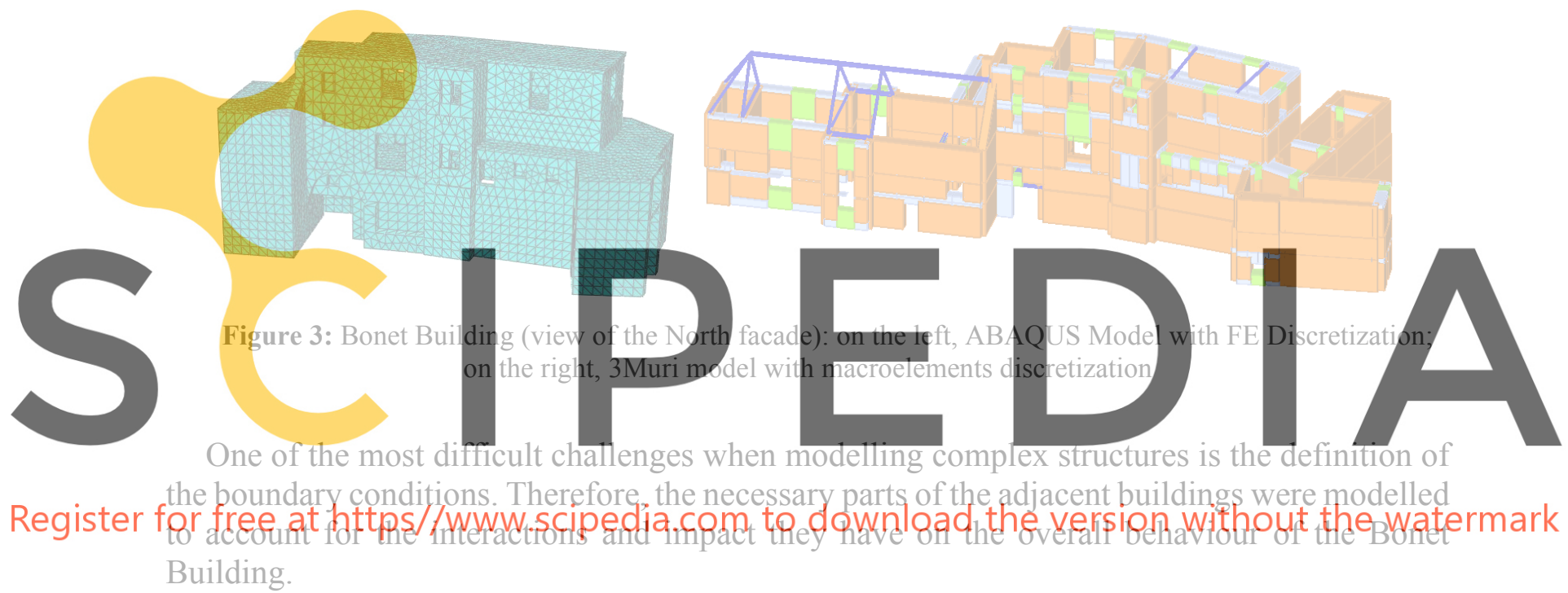

\subsection{Calibration}

The calibration of the numerical models, in ABAQUS and 3Muri, is an important step and fundamental to reach reliable results. In this phase, an iterative process was followed, in which the values obtained in the experimental campaign [3] were considered as reference and in each step special attention was taken to the:

- definition of the boundary conditions, considering the adjacent buildings;

- type of boundary conditions when modelling the structural walls in contact with the bedrock;

- values adopted for the definition of the masses;

- values adopted for Young's modulus (E) of the materials, in particular to the masonry walls (significantly cracked on the top floor and not cracked on the other floors).

Table 1 illustrates the fundamental frequencies for the first three vibration modes obtained experimentally (ARTeMIS) and numerically (ABAQUS and 3Muri), as well the relative error obtained when comparing the numerical to the experimental results, in percentage. Figure 4 
presents the corresponding vibration modes: the first and second mode represent the translational modes in the north-south direction ( $\mathrm{Y}$ - transversal), and the third mode corresponds to the vibration in the east-west direction (X - longitudinal). It is worth noting the close similarity between the frequency values and deformed shapes obtained in the numerical models and the experimental results.

Table 1: Frequencies of first vibration modes, Relative Errors of models in ABAQUS and 3Muri (numerically) in comparison to the model in ARTeMIS (experimentally)

\begin{tabular}{c|c|cc|cc}
\hline & \multicolumn{2}{c}{ ARTeMIS } & \multicolumn{2}{c}{ ABAQUS } & \multicolumn{2}{c}{ 3Muri } \\
\hline Mode: & f (Hz) & f (Hz) & Difference (\%) & $\mathbf{f}(\mathbf{H z})$ & Difference (\%) \\
1st Y & 5.00 & 5.05 & 0.96 & 4.98 & -0.40 \\
2nd Y & 5.18 & 6.17 & 19.11 & 5.55 & 7.14 \\
1st X & 8.20 & 7.27 & -11.34 & 7.03 & -14.27 \\
\hline
\end{tabular}

\begin{tabular}{c|c|c}
\hline \multicolumn{3}{|c|}{} \\
\hline ARTEMIS & ABAQUS & 3Muri \\
\hline
\end{tabular}

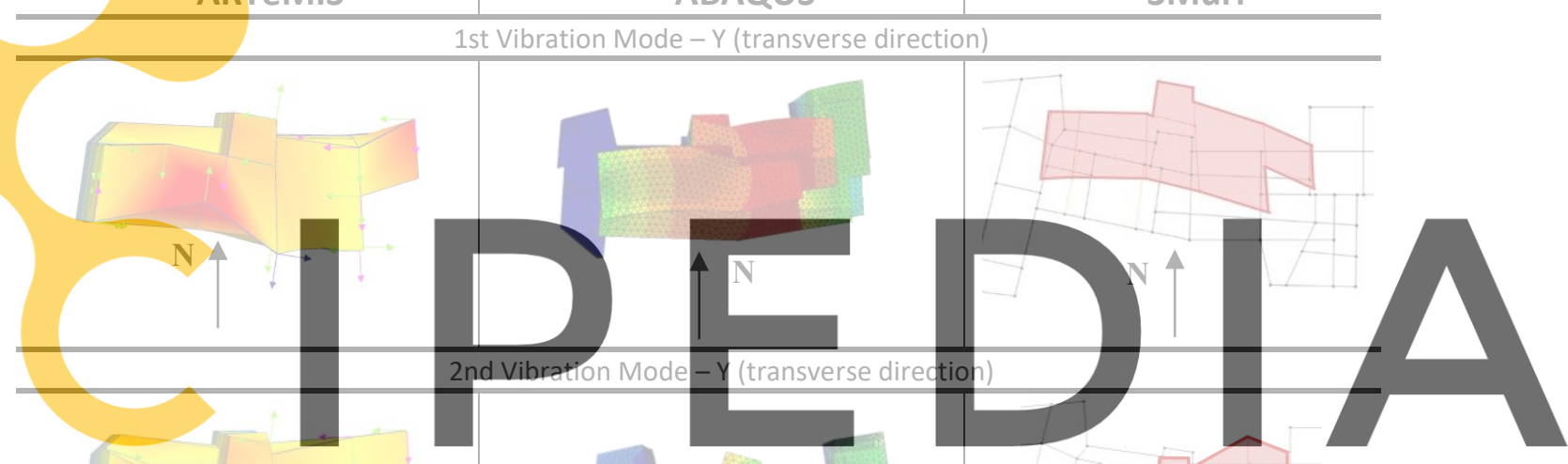

Register for free at https//www.scipedia.com to download the version without the watermark

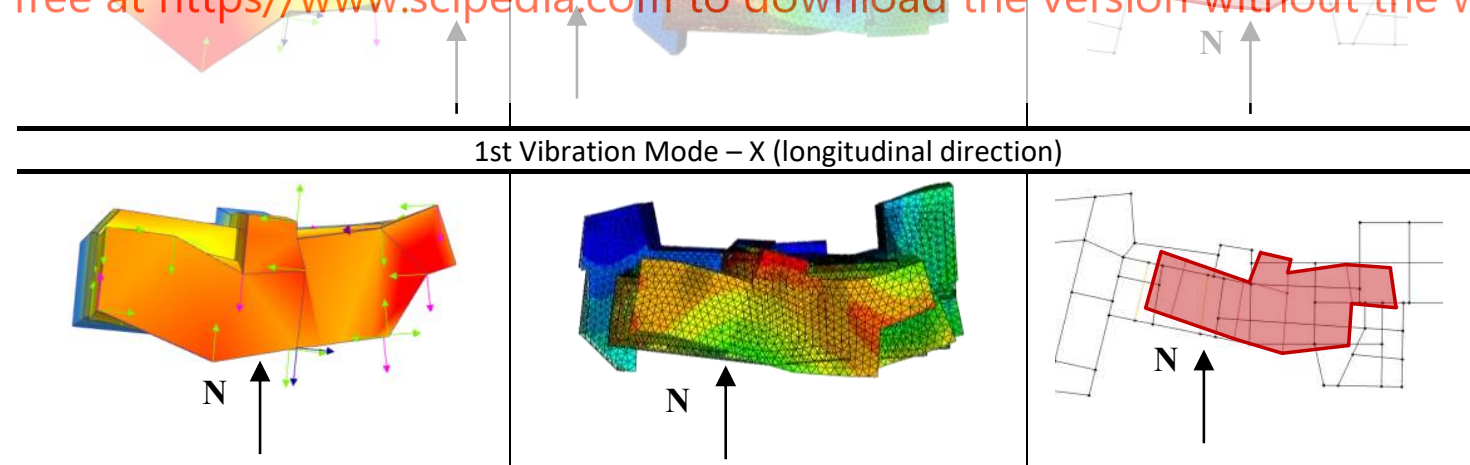

Figure 4 - Deformed shapes of the main vibration modes obtained experimentally (ARTeMIS) and numerically (ABAQUS and 3Muri) - plan view

For the verification of the seismic safety of the structure, nonlinear static analyses were performed. Different approaches were followed to model the nonlinear behaviour of the masonry panels. 
For the Equivalent Frame (EF) models (3Muri program), the masonry panels were modelled as nonlinear beams with lumped plasticity and a piecewise-linear behaviour, that are able to describe the nonlinear response until very severe damage levels through progressive strength decay in correspondence with assigned values of drift [10]. In the EF models, according to the failure modes which can occur, it is possible to use specific failure criteria for the masonry panels. It is highlighted that with this modelling technique only the in-plane behaviour of the walls is considered, assessing the walls' response in terms of global stiffness, strength and ultimate displacement capacity by assuming a proper shear-drift relationship [6]. This relationship depends on the different failure modes, which in turn depend on several parameters: the geometry of the element, the boundary conditions, the axial load, and the mechanical characteristics of the masonry constituents (e.g. mortar and units).

Regarding the FE model (ABAQUS), the masonry walls have been simulated by using the Concrete Damage Plasticity Model (CDPM) and the stress-strain relationships defined separately for compression and tension. The CDPM was designed to define the plastic properties of concrete or quasi-brittle materials developed by Lee \& Fenves [11]. This model uses the concepts of damaged elastic isotropic material in conjunction with the compressive and tensile plastic stress of isotropic material to represent the non-elastic behaviour of masonry, as explored in the ABAQUS Theory Manual [12]. Therefore, it is recommended to be used in masonry materials, despite being developed for concrete. The plastic model assumes that the two main collapse mechanisms are tensile diagonal cracking and compressive crushing. The evolution of the yield surface is controlled by the tensile and compressive strain, considering
different types of behaviour related to the failure meehanisms under load as explained in the
ABAQUS Theory Manual. In this stydy, simplified constitutive laws for compressive and
tensile behaviour were based on [13] and [14], respectively.
The value assumed for the masonry compressive strength was defined proportional to the
calibrated Young's modulus (E). according to MIT [15] reference intervals. The value adopted for the tensile strength was defined as $3 / 2$ of the value of cohesion. The mechanical parameters,

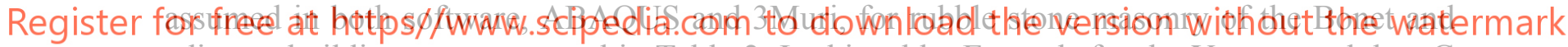
adjacent buildings are presented in Table 2. In this table, E stands for the Young modulus, G for shear modulus, $\mathrm{ft}_{\mathrm{t}}$ for tensile strength, $\mathrm{f}_{\mathrm{c}}$ for compressive strength, and $\mathrm{w}$ for the specific weight of the material.

Table 2: Rubble stone masonry mechanical properties

\begin{tabular}{cccccc} 
& $\mathbf{E}(\mathbf{G P a})$ & $\mathbf{G}(\mathbf{G P a})$ & $\mathbf{f}_{\mathbf{t}}(\mathbf{M P a})$ & $\mathbf{f}_{\mathbf{c}}(\mathbf{M P a})$ & $\mathbf{w}\left(\mathbf{k N} / \mathbf{m}^{\mathbf{3}}\right)$ \\
\hline \multicolumn{7}{c}{ Disorganized irregular stone masonry } \\
\hline MIT (2009) & $0.69-1.05$ & $0.23-0.35$ & $0.030-0.048$ & $1.00-1.80$ & 19 \\
\hline $\begin{array}{c}\text { Bonet Building (Last } \\
\text { Floor) Cracked }\end{array}$ & 0.40 & 0.13 & 0.018 & 0.62 & 18 \\
\hline Bonet Building & 0.80 & 0.26 & 0.036 & 1.24 & 18 \\
\hline & Irregular stone masonry with two external leaves and internal core & \\
\hline MIT (2009) & $1.02-1.44$ & $0.34-0.48$ & $0.053-0.077$ & $2.00-3.00$ & 20 \\
\hline Chapel & 1.44 & 0.48 & 0.080 & 3.00 & 19 \\
\hline Brasões Room & 1.20 & 0.40 & 0.063 & 2.43 & 18 \\
\hline
\end{tabular}


In ABAQUS, damage variables for the compression and tension of each material are necessary to define to control the loss of stiffness and resistance of the material that occurs upon entering the plastic regime, increasing progressively with the stress decay. The damage variables are fundamental to represent the real behaviour of the material during the nonlinear analysis since the damaged masonry presents significant stiffness reductions. A linear progression was adopted since entering the plastic regime until the maximum strain of decay, when it was assigned the maximum damage value of 0.9 .

To define the CDPM in ABAQUS, the values of the following parameters are assumed as being the typical ones for masonry, as explained in [2]: (i) the dilation angle, equal to $10^{\circ}$; (ii) the flow potential eccentricity, set equal to 0.1 ; (iii) the ratio between the initial biaxial compressive yield stress and the initial uniaxial compressive yield stress, set equal to 1.16; (iv) the ratio of the second stress invariant on the tensile meridian and the same on the compressive meridian, set equal to 0.666 ; (v) the viscosity parameter, which defines visco-plastic regularization, equal to 0.002 .

\section{NONLINEAR STATIC ANALYSES}

\subsection{Pushover curves}

In this work, two distributions of lateral loads were considered: uniform - proportional to the mass, and inverse-triangular (named triangular for simplicity) - proportional to the product between the mass and the height of the building. The andyses are performed for the two main directions of the building (longitudinar, $X$, and transversal, $Y$ ) orientation.

Figure 5 presents the base acceleration, and curves corresponds to the ultinate displaceme
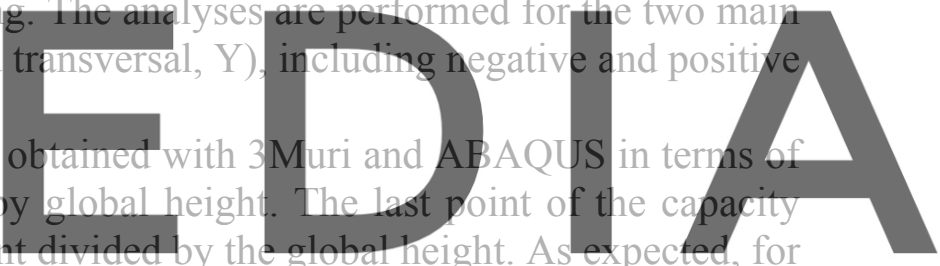

the initial phase, similar values of initial stiffness in pushover curves were obtained for both

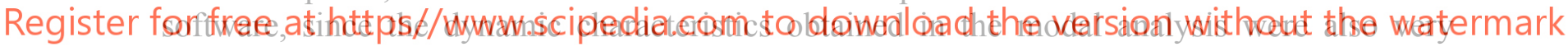
similar.

On the other hand, some differences in terms of maximum base acceleration exist for the curves in the $\mathrm{X}$ direction. For this direction, the curves in 3Muri present less acceleration, that is translated into less strength capacity. This result can be related to the different constitutive laws considered in each software; however, the most likely justification is the fact that in 3 Muri the entirely of the adjacent buildings were modelled, while in ABAQUS only small parts with constraints at its extremities were modelled. The constraints do not allow to consider the damages or even the collapse of the adjacent buildings suffered during the pushover analyses, increasing the strength of the ABAQUS model. This modelling option was made taking into account the computational capacity required to model the entire adjacent buildings in ABAQUS software and the calibration of the model. 

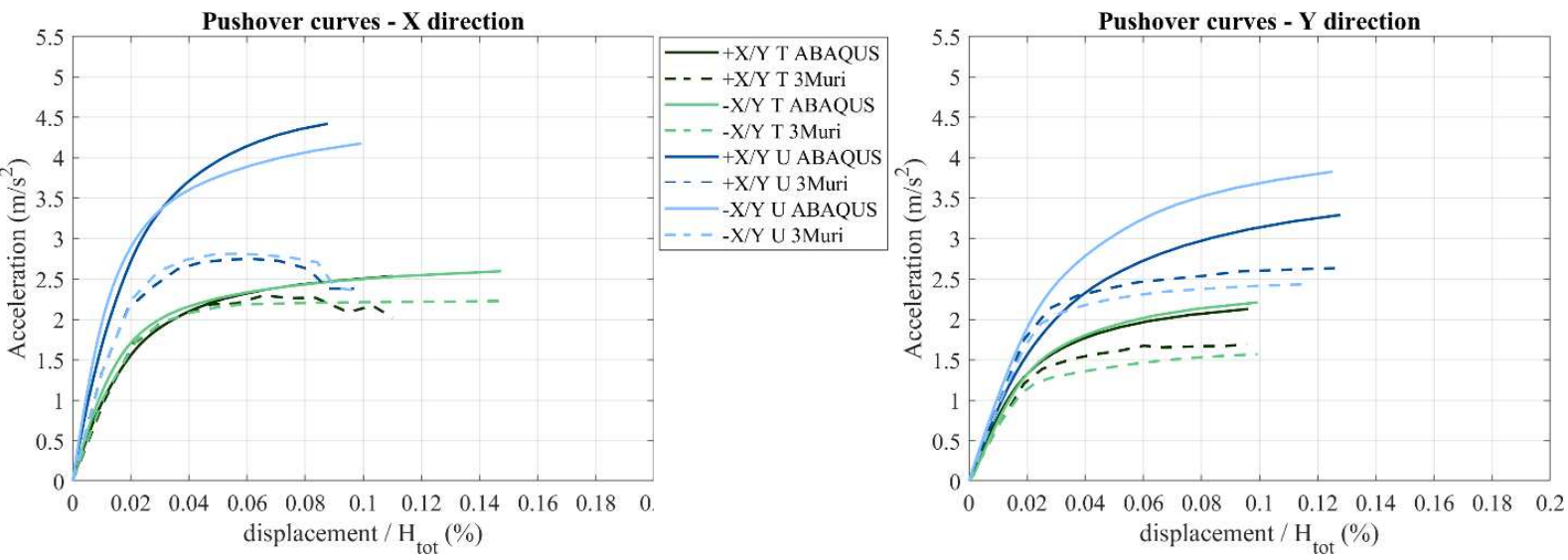

Figure 5: Final Pushover Curves, $\mathrm{X}$ direction (left) and $\mathrm{Y}$ direction (right), ABAOUS and 3Muri

\subsection{Ultimate displacement definition}

The ultimate displacements of the pushover curves obtained in 3Muri were calculated based on two-level multiscale approach: global damage, measured when achieving a decay of $20 \%$ of the base shear force on the pushover curve; and local damage, defined when a collapse mechanism occurs.

The CDPM implids regardless of the damage variab Thus, with the ABA displacement, becoming necessary to define a Since one of the main objectives of the ABAC 3Muri model, in addition to performing the seismic evaluation of Bonet building, the uftimate displacement calculated in 3Muri was used in the corresponding curves obtained in ABAQUS.

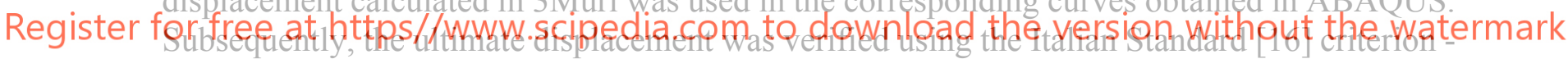

the ratio between the ultimate displacement value and the yield displacement must be between 3 and 6 - and, if necessary, a correction was impiemented.

\subsection{Safety verification - N2 method}

Safety is verified using the N2 method, as suggested in Part 3 of Eurocode 8 [17] and defined in its Part 1 [18]. In this study, for the safety verification, the ratio of the maximum acceleration compatible with the fulfilment of each limit state $\left(a_{g, \max }\right)$ and the reference ground acceleration $\left(a_{g R}\right)$ is evaluated and analysed. The ration between the ultimate displacement and the target displacement was not analysed for the safety verification, since the definition of the ultimate displacement is one of ABAQUS limitations. For the definition of the equivalent single degree of the system (SDOF), a transformation factor needs to be evaluated; as opposed to 3Muri, ABAQUS does not automatically calculate the transformation factor, for this reason, it was obtained manually for each direction, which is a demanding process for complex structures such as the Bonet Building. The degrees of freedom were considered at the floor levels of the structure that are not restrained by the bedrock. The mass associated with each degree of 
freedom was calculated considering the displacements of each floor associated with the vibration modes.

The seismic action was defined according to EC8-1 [18], complemented by the Portuguese Annex. According to EC8-3, three limit states should be considered for the seismic safety verification: Limit Damage (LD), Severe Damage (SD), and Near Collapse (NC).

Safety is verified when the ratio is greater than 1. Figure 6 shows the safety verifications for the type 1 earthquake, the most demanding one, and the near collapse limit state (the one with the highest requirements) of the equivalent SDOF system in ABAQUS and 3Muri. It is then possible to state that safety is not verified for the Bonet Building, with Y direction being the most vulnerable for both models. It should be added that, due to the restrictions of ABAQUS when defining the ultimate displacement, it is more useful and interesting to compare the results of both software in terms of damage patterns, as will be commented below.
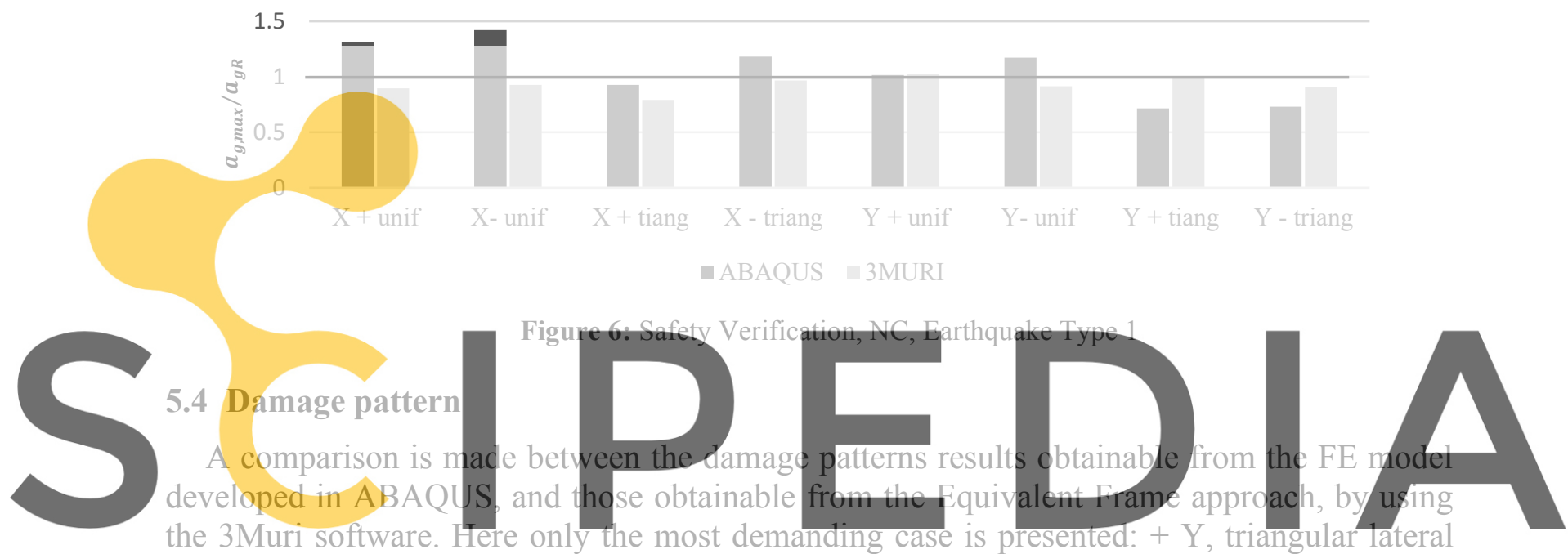
load distribution (Figure 7 and Figure 8). The damage patterns depicted correspond to the

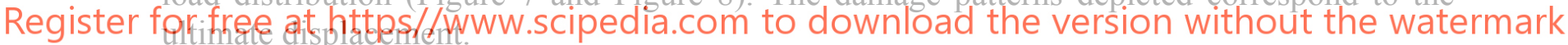

According to the 3Muri results presented in Figure 7, it is possible to identify in the Bonet building a concentration of damaged elements at the top floor, even with a pier collapsed due to shear on the western sidewall. The walls of the top floors along the Y direction present damage mainly due to shear behaviour. As expected, the type of collapse is severely influenced by the height/length ratio; walls with lower values are controlled by shear, while walls with higher ratio values tend to present flexural damage.

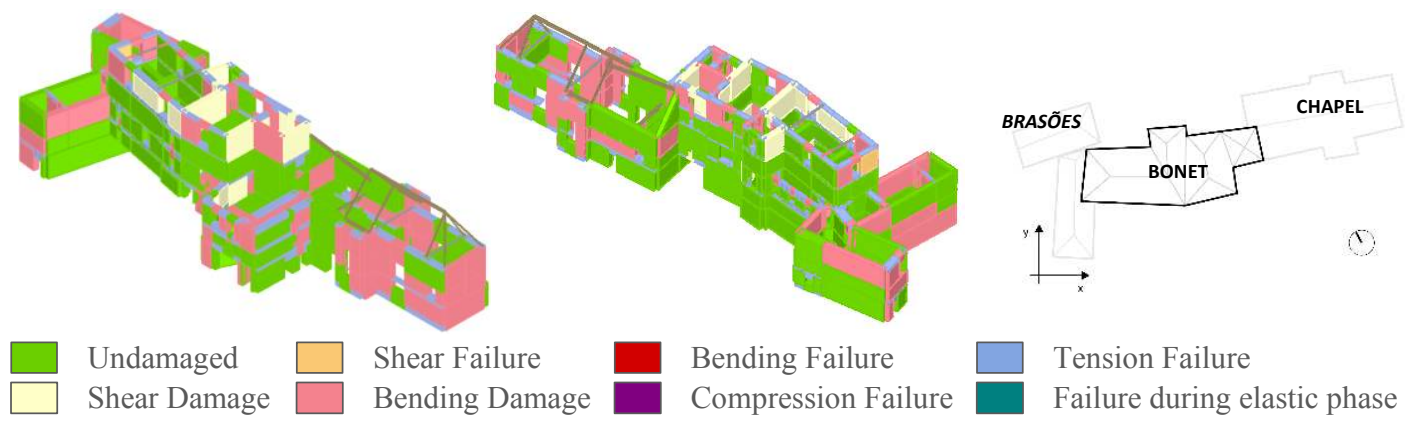

Figure 7: Damage Pattern, 3Muri (+Y, triangular distribution) - damage in Equivalent Frame Model 

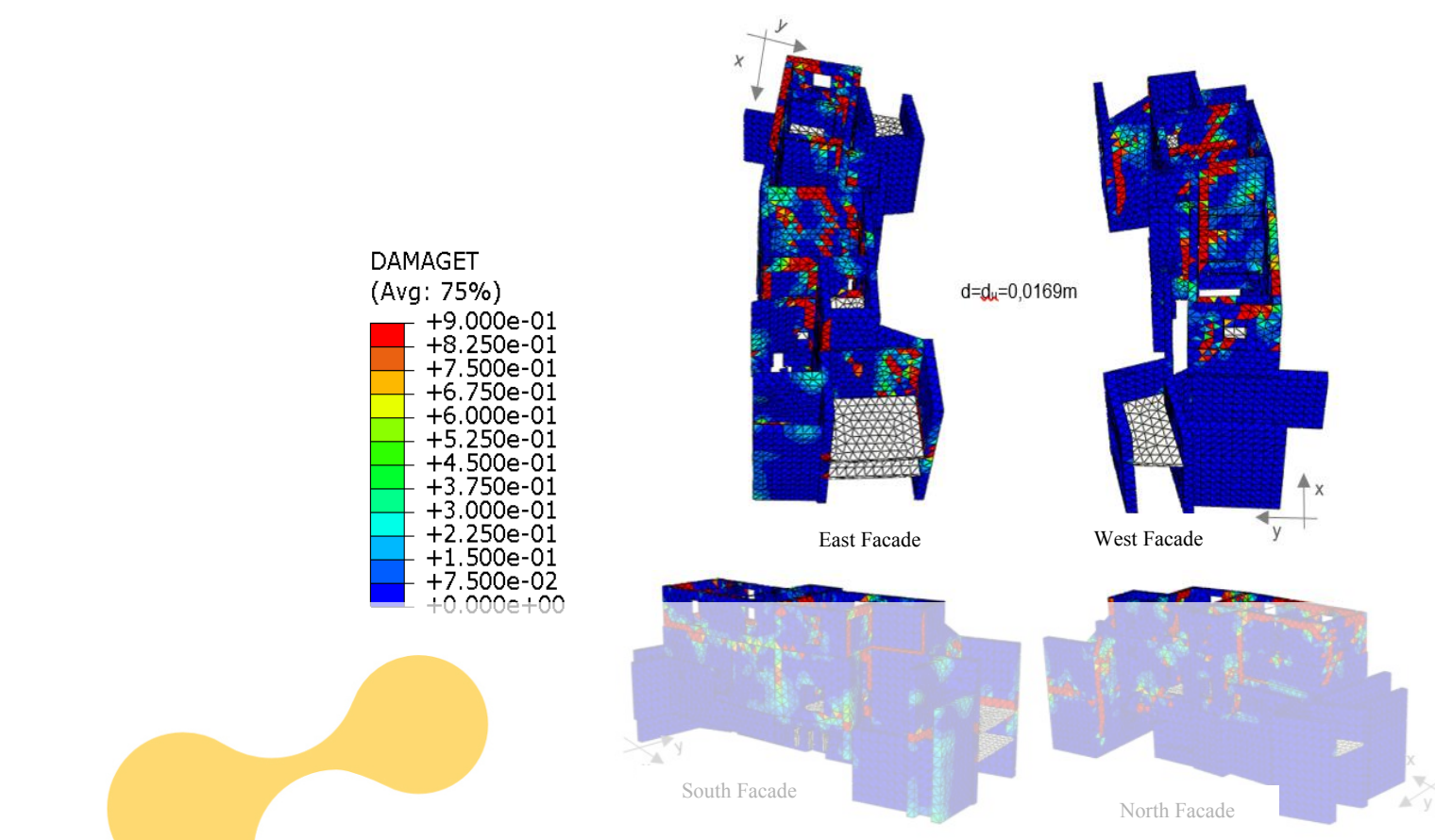

Figure 8: Damage Pattern, principal inelastic Tensile strains, ABAQUS (+Y, triangular distribution)

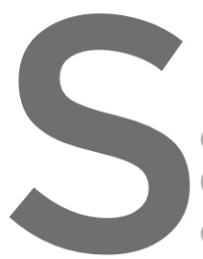

Finite element analy
n the other side, refini
mplex structures of $t$
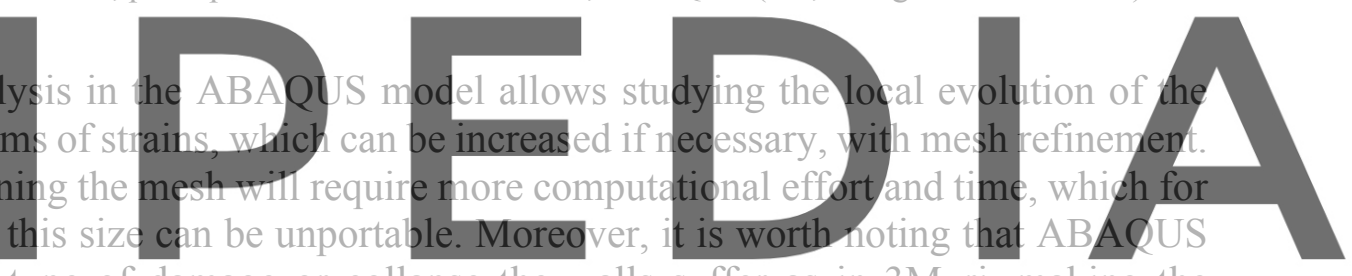

does not identify the type of damage or collapse the walls suffer as in 3Muri, making the

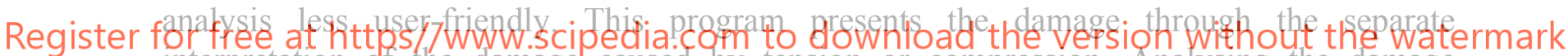
interpretation of the damage caused by tension or compression. Analysing the damage parameter in ABAQUS for the tensile strains (Figure 8), it can be concluded that most of the damage is also concentrated on the walls of the top floor. The diagonal inclination of the cracks at the top floor walls along the $\mathrm{Y}$ direction clearly indicates the activation (or close to the activation) of shear failure, as seen in 3Muri damage patterns. It is worth mentioning that the maximum tensile damage is presented in the upper spandrels of the last floor walls, in both facades, where the tie rods are located. This effect cannot be identified in 3Muri since a global analysis is performed, without considering the out-of-plan behaviour.

In the past, some numerical comparisons have already been carried out for masonry walls ([19], [20]) and the results have shown generally good agreement in terms of damage pattern. This is in accordance with the observed in the Bonet building analyses for FE and EF models.

\section{CONCLUSIONS}

Regardless of the numerical software used, the point cloud based on the laser scanner survey is essential for the correct geometric characterization of a complex building. As the construction of complex structures in ABAQUS is very difficult, it is suggested, whenever possible, to import a BIM model of the structure directly into the software. Otherwise, it may not be 
advisable to use ABAQUS to assess this type of structures, as the effort of building the numerical model will not be worthwhile. Moreover, the BIM model has to be architecturally simplified and built in order not to create distorted finite elements when generating the mesh in the FEM software. On the other hand, 3Muri is a program developed for masonry building modeling and analysis, leading to a simplified process of construction and alteration of the geometric characteristics of the structure.

In general, good correspondence is observed between the predictions of the two numerical models considered. Note that ABAQUS presents a high graphical ability to observe the results. In the modal analysis, it is possible to rigorously study the deformed structure for the various vibration modes. The same conclusion can be drawn when interpreting the damage pattern since one can observe the damage evolution for each finite element node, while 3Muri presents the damage evolution for each macroelement. However, 3Muri designates the type of damage or collapse in each element, which is very useful to the user.

In addition, 3Muri is a more suitable program for performing pushover analysis and subsequent security verifications. The program proposes for each analysis an ultimate displacement and automatically calculates the transformation factor of the models from MDOF to SDOF. These two points are of high difficulty in ABAQUS, involving a complex calculation, especially for complex buildings. On the other hand, in ABAQUS, non-linear analyses performed with refined FE discretizations of the critical regions and with more sophisticated material models, are useful to deepen the knowledge of the behaviour of complex structures under seismic actions.

Lastly, 3Muri does not require the large computational effort and time that ABAQUS requires, which is a very important aspect to take into account when dealing with very large and complex structures. In the end, it will be necessary for the user to choose between more geometry accuracy and detail with ABAQUS or less computational effort with 3Muri.

Acknowledgements. The authors wish to thank the IST and PSML teams involved in the project. In addition, the first author would like to acknowledge the financial support of the Portuguese Foundation for Science and Technology (Ministry of Science and Technology of the Republic of Portugal) through a PhD scholarship [grant number SFRH/BD/145571/2019]. The authors also thank Simone Tiberti and Gabriele Milani from Politecnico di Milano, who provided insight and expertise that greatly assisted the development of the model in ABAQUS.

\section{REFERENCES}

[1] Sarhosis, V., Milani, G., Formisano, A. and Fabbrocino, F. Evaluation of different approaches for the estimation of the seismic vulnerability of masonry towers. Bull. Earthq. Eng. (2017) 16(3):1511-45.

[2] Degli Abbati, S., D’Altri, A.M., Ottonelli, D., Castellazzi, G., Cattari, S., de Miranda, S. and Lagomarsino, S. Seismic assessment of interacting structural units in complex historic masonry constructions by nonlinear static analyses. Computers and Structures (2019) 213:72-81. https://doi.org/10.1016/j.compstruc.2018.12.001

[3] Ponte, M., Bento, R., Silva, D.V. A multi-disciplinary approach to the seismic assessment of the National Palace of Sintra. International Journal of Architectural Heritage (2019). https://doi.org/10.1080/15583058.2019.1648587 
[4] Bento, R. An interdisciplinary approach to the seismic assessment of built cultural heritage: Case studies in Lisbon and outskirts. In: R. Aguilar et al. (Eds.): Structural Analysis of Historical Constructions, RILEM Bookseries 18 (2019), pp. 3-18. Cham: Springer. 10.1007/978-3-319-99441-3_1.

[5] ARTeMIS Modal Pro (version 3.0). 2013. Aalborg: Structural Vibration Solutions A/S.

[6] 3Muri (version 11.4.0). 2018. S.T.A. DATA.

[7] ABAQUS CAE (version 16.14-1). Complete Solutions for Realistic Simulation (2014).

[8] Querido, J. O Edifício Bonet do Palácio Nacional de Sintra: Caracterização e avaliação do desempenho estrutural. MSc thesis, Instituto Superior Técnico, Universidade de Lisboa (2018). Lisboa. (in Portuguese)

[9] Castellazzi, G., D’Altri, A.M., Bitelli, G., Selvaggi, I., and Lambertini, A. From laser scanning to finite element analysis of complex buildings by using a semi-automatic procedure. Sensors (2015) 15(8): 18360-18380. https://doi.org/10.3390/s150818360

[10] Lagomarsino, S., Penna, A., Galasco, A., and Cattari, S. TREMURI program: An equivalent frame model for the nonlinear seismic analysis of masonry buildings. Engineering $\quad$ Structures $\quad$ (2013) $\quad$ 56: http://dx.doi.org/10.1016/j.engstruct.2013.08.00

[11] Lee, J. and Fenves, G.L. Plastic-Damage Model for Cyclic Loading of Concrete Structures. Journal of Engineering Mechanics (1998) 124(8): 892-900. https://doi.org/10.1061/(ASCE)0733-9399(1998)124:8(892)

[12] Simulia. ABAQUS Theory Manual. Version 6.6. (2014)

[13] Kaushik, H.B., Rai, D.C., and Jain, S.K. Uniaxial compressive stress-strain model for clay brick masonry. Current Science (2007) 92: 497-501.

[14] Dhanasekar, M., and Haider, W. Explicit finite element analysis of lightly reinforced masonry shear walls. Computer and Structures (2008) 86: 15-26. https://doi.org/10.1016/j.compstruc.2007.06.006

[15] MIT. Circolare n. 617 del 2 Febbraio 2009. Istruzioni per l'Applicazione Nuove Norme Tecniche Costruzioni di cui al Decreto Ministeriale 14 Gennaio 2008 (2009). (in Italian).

[16] NTC. Norme Tecniche per la Construzioni (NTC). Decreto Ministeriale 17/01/2018, Official Gazette (2018). Roma (in Italian).

[17] CEN. NP EN 1998-3: Eurocódigo 8 - Projecto de estruturas para resistência ao sismo. Parte 3: Avaliação e Reabilitação de edifícios. Instituto Português da Qualidade. European Committee for Standardization, (2017). Retrieved from http://www.iso.org/iso/foreword.html (in Portuguese)

[18] CEN. NP EN 1998-1: Eurocódigo 8 - Projecto de Estruturas para resistência aos sismos. Parte 1: Regras gerais, acções sísmicas e regras para edifícios. Instituto Português da Qualidade. European Committee for Standardization, (2009). (in Portuguese)

[19] Calderini, C., Cattari, S., Lagomarsino, S. In-plane seismic response of unreinforced masonry walls: comparison between detailed and equivalent frame models. In: Proc. of Int. Conf. on Computational Methods in Structural Dynamics and Earthquake Engineering (COMPDYN 2009), Rhodes, Greece, (2009).

[20] Camilletti, D., Cattari, S., Lagomarsino, S. (2018). In plane seismic response of irregular URM walls through equivalent frame and finite element models. In: $16^{\text {th }}$ European Conference on Earthquake engineering (16ECEE), Thessaloniki, Greece, (2018). 